This item was submitted to Loughborough's Research Repository by the author.

Items in Figshare are protected by copyright, with all rights reserved, unless otherwise indicated.

\title{
Estimation of reaction forces in high bar swinging
}

PLEASE CITE THE PUBLISHED VERSION

PUBLISHER

Springer / @ ISEA

VERSION

AM (Accepted Manuscript)

LICENCE

CC BY-NC-ND 4.0

\section{REPOSITORY RECORD}

Kerwin, David G., and Michael J. Hiley. 2019. "Estimation of Reaction Forces in High Bar Swinging". figshare. https://hdl.handle.net/2134/6528. 
This item was submitted to Loughborough's Institutional Repository (https://dspace.lboro.ac.uk/) by the author and is made available under the following Creative Commons Licence conditions.

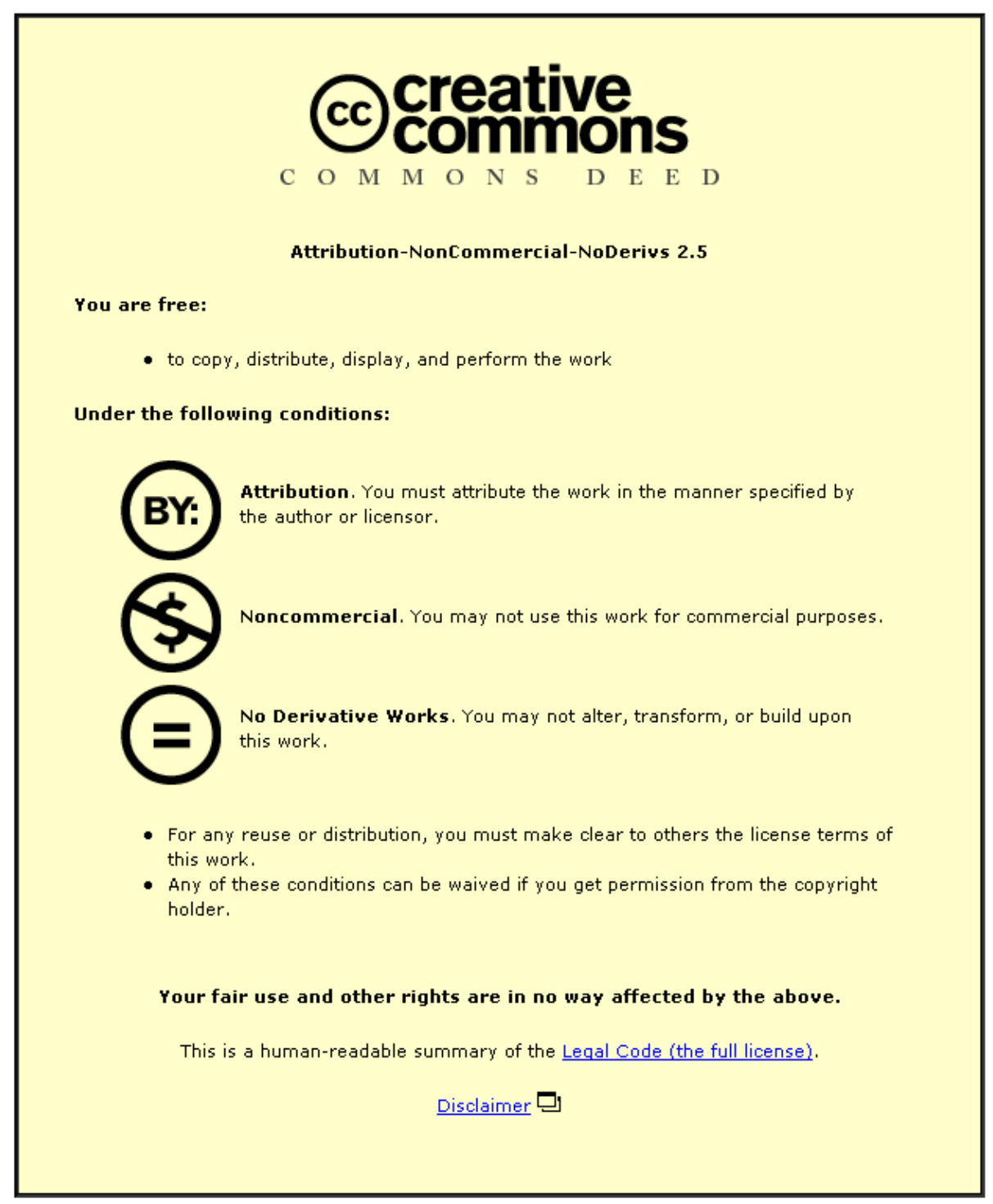

For the full text of this licence, please go to: http://creativecommons.org/licenses/by-nc-nd/2.5/ 


\title{
ESTIMATION OF REACTION FORCES IN HIGH BAR SWINGING
}

\author{
D.G. Kerwin ${ }^{1}$ and M.J. Hiley ${ }^{2}$ \\ ${ }^{1}$ Department of Sport and Exercise Science, University of Bath, Bath, BA2 7AY, Avon, UK \\ ${ }^{2}$ Department of Sports Science, Loughborough University, LE11 3TU, Leicestershire, UK
}

\begin{abstract}
Reaction forces experienced by gymnasts swinging on the high bar may be determined indirectly using inverse dynamics analysis or may be measured using strain gauges. The accuracy of inverse dynamics analysis may be poor due to errors in the estimated inertia parameters and in the accelerations obtained from digitised data. On the other hand the use of strain gauges is not always possible in elite competition. This paper presents a method for estimating the reaction forces based on the linear displacements of the bar. The bar was modelled as a point mass attached to horizontal and vertical linear springs (obeying Hooke's Law) with stiffness coefficients determined from static loading. The stiffness coefficients of the bar were determined with three different tensions in the stabilising cables of the high bar. A force and video analysis of backward giant circles was performed. Estimates for the reaction forces were obtained by multiplying the bar displacements from the video analysis by the stiffness coefficients determined from the static loadings. Comparisons were made between the estimated reaction forces and the reaction forces recorded using strain gauges attached to the high bar. Varying the tension in the stabilising cables of the high bar did not effect the stiffness of the bar. Root mean squared differences between estimated and recorded reaction forces were on average within $99 \mathrm{~N}$ for three 'regular' and three 'accelerated' giant circles. This was less than $3.5 \%$ of the range of forces recorded. The bar displacement method was able to estimate the peak reaction forces to within $7 \%$ on average, which compares favourably with $24 \%$ reported by Gervais (1993) using inverse dynamics.
\end{abstract}

Keywords : biomechanics, gymnastics, high bar, reaction forces

\section{Introduction}

The high bar (or horizontal bar) is one of the six competition pieces of apparatus in Men's Artistic Gymnastics. The regulations set down by the International Federation of Gymnastics (FIG) require the bar to be made from stainless steel $2.4 \mathrm{~m}$ long and $0.028 \mathrm{~m}$ in diameter (Fig 1.) The bar is $2.55 \mathrm{~m}$ above a mat, which is $0.20 \mathrm{~m}$ deep, and is held in position by two supporting uprights which are stabilised by four tensioned cables. Under a central load of $2200 \mathrm{~N}$ the bar must produce a vertical deflection of $0.10 \mathrm{~m} \pm 0.01 \mathrm{~m}$. When the load is removed the bar must resume a straight line with no deviations from its original shape (FIG, 1993). Although there is no recommendation regarding the tension in the stabilising cables they must be capable of withstanding a load of $8000 \mathrm{~N}$. 


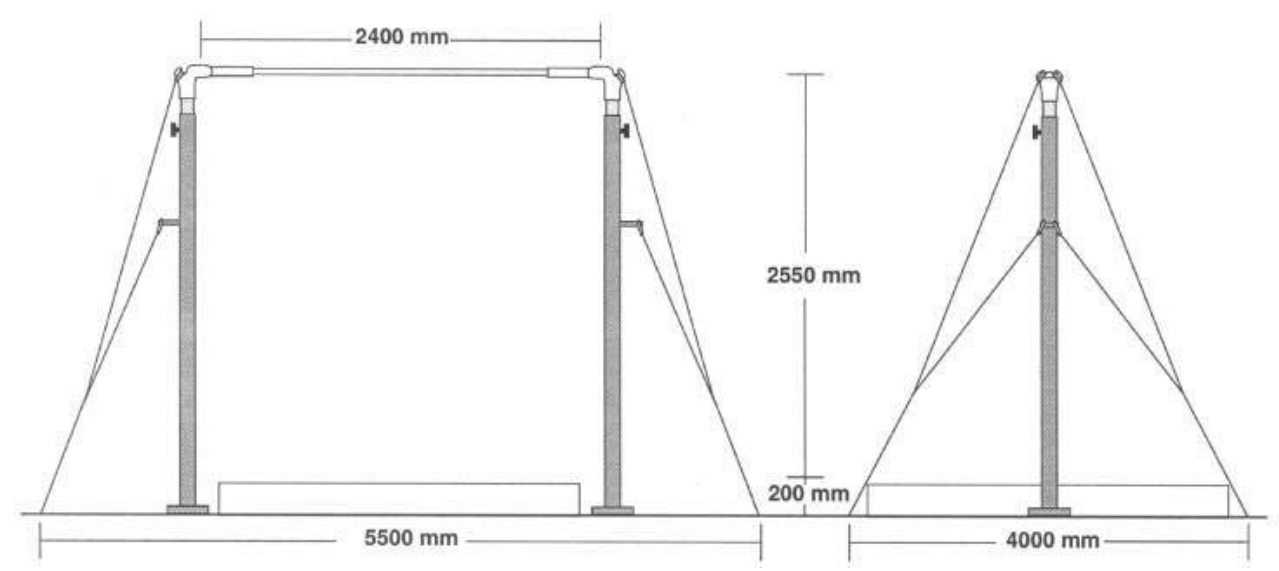

Figure 1 Competition high bar with dimensions specified by the sport's governing body.

The backward giant circle on high bar is used to link circling skills and to provide the rotation for the release and dismount skills. The basic technique of the backward giant circle requires the gymnast to make adjustments to the shoulder and hip joints as he rotates around the bar. There is a characteristic body 'arch' followed by a 'dish' as he passes through the lower portion of the circle which is followed by an extension of the body as he passes through the higher part of the circle (Fig. 2). A giant circle in which the aim of the gymnast is merely to swing from the handstand position above the bar back to handstand is referred to as a 'regular' giant circle. In an 'accelerated' giant circle the gymnast tries to increase his rotation about the bar prior to a release or dismount. When a gymnast swings, the bar has been shown to "bend" in the region of $0.10 \mathrm{~m}$ (Brüggemann et al., 1994).

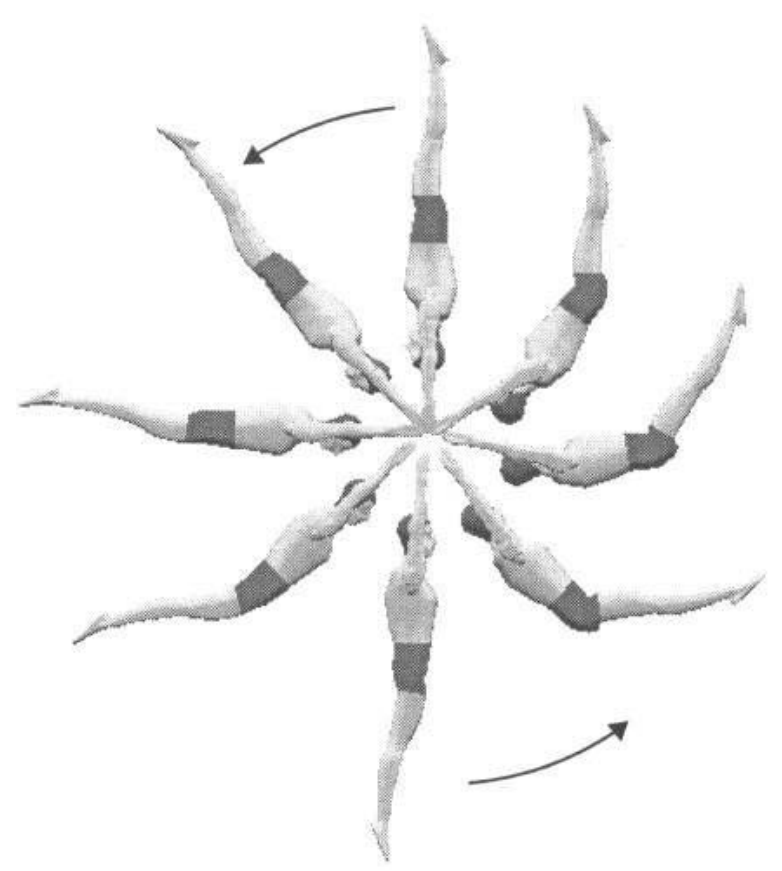

Figure 2 The backward giant circle where the gymnast swings from handstand to handstand.

Gymnasts experience high forces when performing giant circles on the high bar. These forces can be measured using strain gauges mounted on the bar (Enchun, 1989; Gervais, 1993; Ishii and Komatsu, 1987; Kopp and Reid, 1980; Neal, et al., 1995). Using strain 
gauges in the competitive environment is rarely possible due to the invasive nature of the gauges (they must be bonded to the bar) and the associated cabling and data recording systems required. However, the measurement of forces using strain gauges has been permitted during at least one major gymnastics competition (e.g. Arampatzis and Brüggemann, 1999). As an alternative, the reaction forces during high bar performances may be calculated using inverse dynamics analysis (Gervais, 1993). The method of inverse dynamics analysis relies on estimated segmental inertia parameters and accelerations obtained from digitised data. Errors arising from the use of inappropriate body segment parameters and errors in accelerations estimated from noisy displacement data can lead to errors in the estimated forces using the inverse dynamics method.

The FIG requirements suggest that the high bar behaves like a linear spring (based on Hooke's Law). If this is the case the displacement in the bar would be proportional to the load applied to it. If the relationship between displacement and load were known it would be possible to estimate the reaction forces from the linear displacements of the bar obtained from video analysis. Kopp and Reid (1980) calibrated strain gauges mounted to a high bar using known loads. The relationship between load and voltage was linear. Since the voltage output is related to the strain in the high bar it may be speculated that the relationship between load and bar displacement is also linear. There are no regulations set out by the FIG which specify the elastic properties of the bar in the horizontal direction nor are there any figures provided for the tension in the cables which stabilise the uprights. Neal et al. (1995) calibrated a high bar in the horizontal direction by turning the bar through $90^{\circ}$ and loading it in the vertical direction but this neglects any differential effect of the cables on the horizontal and vertical stiffness. In the norms testing manual supplied by Continental Sports Ltd, UK (1994, an FIG approved manufacturer) during static and dynamic loading of the bar the tension in the cables is set to $1400 \pm 100 \mathrm{~N}$ and $1500 \pm 100 \mathrm{~N}$, respectively, before testing is started. The tension in the cables may effect the stiffness of the high bar which in turn may have implications for the gymnast's technique.

The overall purpose of the study was to estimate reaction forces from the displacement of the high bar obtained from a video analysis of backward giant circles. To achieve this aim four prerequisites were necessary; to determine whether the bar could be modelled as a linear spring with stiffness values within the required FIG limits; to investigate whether the bar was equally stiff in the horizontal and vertical directions; to determine whether bar stiffness was affected by the tension in the cables and to evaluate a field based static calibration procedure for providing stiffness values for the high bar.

\section{Methods}

\section{Data collection}

The data collection involved static loading of the high bar where known loads were applied to the bar and the horizontal and vertical displacements of the bar were determined. In a separate testing session a kinetic and kinematic analysis of a gymnast performing regular and accelerated giant circles was carried out.

\section{Equipment}

A competition high bar (Continental Sports Ltd, UK) was erected and the uprights were made vertical using spirit levels. A calibrated load cell was placed within each of the four stabilising cable and chain systems. The load cells were constructed from $7 \mathrm{~mm}$ mild steel with the middle section milled down to $3 \mathrm{~mm}$. Each side of the plate had two strain gauges cross paired at $90^{\circ}$ (FCA-3, Techni Measure Ltd) which were wired to form a full 
Wheatstone bridge. Each of the four load cells was connected to a strain gauge amplifier (Modular 600). The load cells were calibrated by loading them to $3.0 \mathrm{kN}$ in steps of $0.2 \mathrm{kN}$ using an Instrom (model 8011) hydraulic testing machine.

To record the force whilst the gymnast circled the high bar, 16 linear strain gauges (CEA/09/280UW/120) were bonded to the surface of the bar (Fig. 4a). The gauges were arranged into two full Wheatstone bridge systems at each end of the bar, one bridge to measure horizontal strain and one bridge to measure vertical strain. The arrangement of the bridges resulted in four channels of data. The bridges were connected to a four channel strain gauge amplifier (Model 2100, Measurement Group UK) and the amplified signals were passed through a 12-bit analogue-to-digital converter (Cambridge Electronic Design, UK, CED 1401). The collection of strain data was triggered using a photocell and reflector attached to the uprights of the high bar. During the dynamic trials, as the gymnast passed through the lowest point on the first giant circle his hips broke the beam triggering the strain data collection. The software controlling the data recorder was designed to collect data one second before and $6.5 \mathrm{~s}$ after the trigger was activated. The delayed trigger allowed strain data to be recorded during the downswing of the first giant circle. All strain data were recorded at $200 \mathrm{~Hz}$ over a period of $7.5 \mathrm{~s}$.

The linear displacements of the bar during the static and dynamic testing were recorded using two video cameras, a Sony Hi8 Hyper HAD (EVW-300P) and a Sony Digital Handycam (DCR-VX1000E), both operating at $50 \mathrm{~Hz}$. The cameras were genlocked in order to synchronise their shutters which were operating at $1 / 500 \mathrm{~s}$ and $1 / 600 \mathrm{~s}$ respectively. The two cameras were located approximately $1.6 \mathrm{~m}$ above the ground at a distance of $8.5 \mathrm{~m}$ from the centre of the high bar (Fig. 3). For the static loading of the bar the width of the field of view was set to approximately $2 \mathrm{~m}$ with the centre of the bar in the centre of the image. For the dynamic testing the camera lenses were 'zoomed out' to give a $6 \mathrm{~m}$ wide field of view (large enough to view a gymnast circling the high bar). An array of light emitting diodes (LEDs) was placed in view of both cameras. The LED array was connected to the high bar strain data capture trigger, illuminating each time the photocell beam was broken. This allowed the video data to be synchronised with the strain data and also provided common events in each camera view.

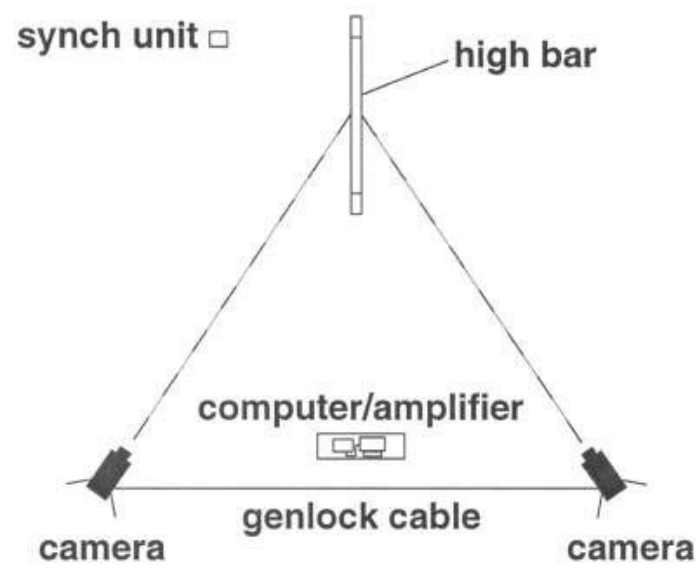

Figure 3 Location of the cameras used in the three dimensional analysis of the backward giant circles.

Prior to the gymnast performing giant circles and the static loading, a calibration structure comprising 28 spheres of diameter $0.08 \mathrm{~m}$ placed in known locations and encompassing a volume measuring $1 \mathrm{~m} \times 5 \mathrm{~m} \times 5 \mathrm{~m}$ was positioned with its centre at the midpoint of the high bar. The structure was designed to include the motion of the gymnast 
performing giant circles within the calibrated volume. The calibration structure was video recorded from both camera views.

\section{Static calibration}

The bar was loaded vertically at its centre using chains and two bottle screws (Fig. 4a). The bottle screws were the same type as those used to tighten the cables stabilising the uprights of the high bar. One end of the loading system was connected to the centre of the high bar using terylene loops. The other end was connected to a floor plate mounted directly beneath the centre of the bar (Fig. 4a). A load cell was placed in series with the chains of the loading system to measure the force applied to the bar (Fig. 4a). The load cell was connected to a strain gauge amplifier (Tinsley Sovereign) which gave an analogue display of the strain. To load the bar in the horizontal direction two eye bolts were mounted at bar level into the steel super-structure of the laboratory (Fig. 4b). The loading system was connected between the high bar and the wall mounted eye bolts (Fig. 4b).

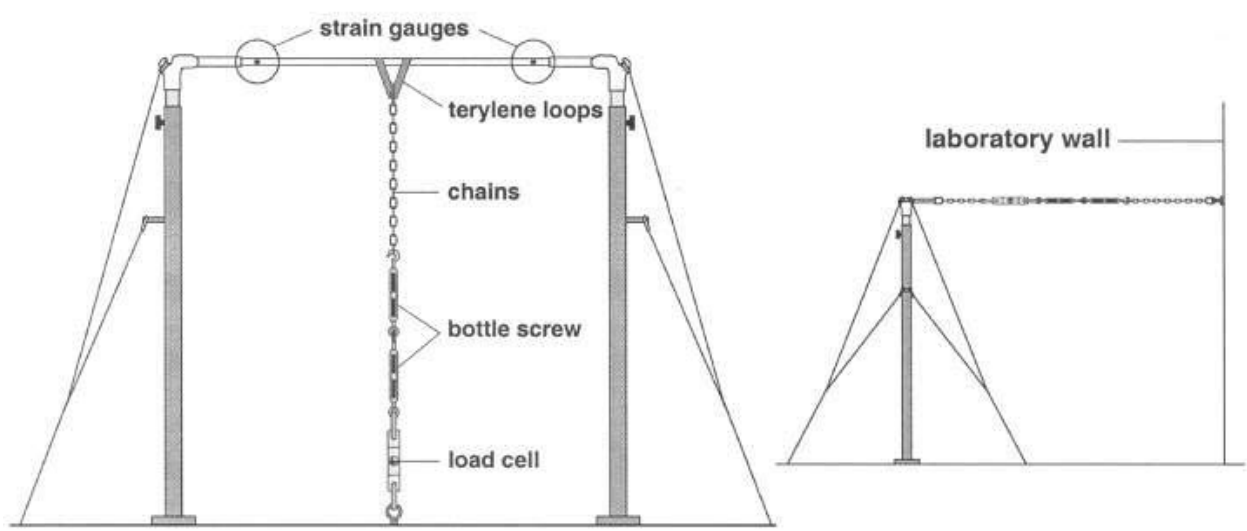

(a)

(b)

Figure 4 System of chains and links incorporating a load cell used to load the bar during static loading in the vertical (a) and horizontal (b) directions.

The bar was loaded vertically to $3.0 \mathrm{kN}$ in steps of $0.5 \mathrm{kN}$. This was achieved by tightening the bottle screws within the loading system. When the amplifier connected to the load cell within the loading system gave the appropriate reading a video recording of the high bar was taken. To increase the number of data points video recordings were also made as the bar was unloaded. In the horizontal direction the bar was loaded to $2.5 \mathrm{kN}$ in steps of $0.5 \mathrm{kN}$.

The field based method of statically calibrating the bar involved a swing being suspended from the centre of the bar. The swing was loaded incrementally with four adults. Each time a new person was added to the static swing a video recording of the bar was made. As with the static loading procedure, recordings were also made as the bar was unloaded. No 'field' loading was performed in the horizontal direction.

The static and field based calibration procedures were performed three times. Initially the tension in the stabilising cables was set to $1.5 \mathrm{kN}$. In the repeated calibrations the tension in the stabilising cables was set to $1.7 \mathrm{kN}$ and $1.3 \mathrm{kN}$ respectively. These equate to twice the deviation permitted in the FIG norms testing on either side of the target tension $(1.5 \mathrm{kN})$, giving a range of cable tension within which a the high bar is likely to be used. 


\section{Calibration of bar mounted strain gauges}

The same loading and unloading procedure used in the static calibration (3.0 kN and $2.5 \mathrm{kN}$ in the vertical and horizontal directions respectively) was used to calibrate the strain gauges. Once the appropriate load was applied to the bar, data were recorded from the bar mounted strain gauges. The tension in the stabilising cables was not monitored using the 'in series' load cells since this would not be possible in the field.

After calibration one senior male elite competitive gymnast performed several regular and accelerated backward giant circles on the high bar while force and video data were collected.

\section{Data Analysis}

\section{Static loading}

The centres of the calibration spheres were digitised in five fields from both camera views. All digitising was carried out with the Target high resolution digitising system (Kerwin, 1995). At each load the centre of the bar was digitised in ten video fields. The locations of the centre of the bar were reconstructed using the three-dimensional Direct Linear Transformation procedure (Abdel-Aziz and Karara, 1971).

A linear regression was performed on the vertical bar displacements and the load applied to the bar. Since no vertical displacement occurred when zero load was applied to the bar, the regression was forced through the origin. Using Hooke's Law, the gradient of the regression line was used to determine the stiffness coefficient of the bar. The same procedure was carried out for the data collected in the horizontal direction.

\section{Dynamic bar displacements}

The centres of the calibration spheres were digitised in five fields from both camera views. The marked centre of the bar between the subject's hands was digitised for each camera view in three regular and three accelerated giant circles. The data obtained from digitising the images of the calibration spheres together with their known locations were used to calculate the 11 Direct Linear Transformation parameters for each camera (Abdel-Aziz and Karara, 1971). The synchronised digitised coordinate data from each camera view along with the camera parameters were used to reconstruct the three-dimensional locations of the centre of the bar using the Direct Linear Transformation procedure (Abdel-Aziz and Karara, 1971). Quintic splines (Wood and Jennings, 1979) were used to fit the horizontal and vertical bar displacements.

\section{Dynamic loading}

The strain data recorded from the two ends of the bar were combined during all procedures. This meant that the strain and subsequent force would be independent of the point of application of the load along the bar. Linear regressions were performed between the load applied to the bar and the recorded strain separately for the vertical and horizontal directions. The regressions were forced through the origin since all the amplifier channels had been zeroed with no force applied to the bar. The strain data recorded during the backward giant circles were converted into force (Newtons) using the regression equations obtained above.

\section{Synchronisation of the force and video data}

The force and video data were collected simultaneously. The force data were recorded at $200 \mathrm{~Hz}$ whilst the video data were recorded at $50 \mathrm{~Hz}$. The photocell, which gave a voltage output when the beam was broken, was used to trigger the force capture and illuminate the 
LED array. The photocell trigger and LED array allowed the force and video data to be synchronised to the nearest video field. The video field corresponding to the first illumination of the LED array was matched to the force data point corresponding to the trigger of the force data collection. This meant that the force and video data were synchronised to the nearest video field. Since video fields are separated by $0.02 \mathrm{~s}$ (recorded at $50 \mathrm{~Hz}$ ) the synchronisation of the force and video data was to within $0.01 \mathrm{~s}$.

\section{Estimating reaction forces}

The stiffness coefficients obtained from the static loadings were used with the bar displacements to estimate the reaction forces at the bar during three regular and three accelerated giant circles. The root mean squared (rms) differences between the estimated and measured forces were determined for each trial. In addition the differences between the estimated and the measured peak forces were calculated.

\section{Results and Discussion}

\section{Static loading}

The results of the linear regressions performed on the data from the static loadings are given in Table 1. The terms 'slack', 'normal' and 'tight' in Table 1 refer to cable tensions of $1.3 \mathrm{kN}, 1.5 \mathrm{kN}$ and $1.7 \mathrm{kN}$ respectively. The relationships between applied load and bar displacement are shown in Fig. 5 and can be seen to be linear. The minimum adjusted $\mathrm{R}^{2}$ value for all regressions was 0.998 . From the requirements set out by the FIG the bar should have a stiffness coefficient of between 20,000 N.m ${ }^{-1}$ and 24,444 N.m ${ }^{-1}$. The type of competition high bar used in the present study was subjected to norms testing by the FIG. Under a load of $2200 \mathrm{~N}$ the bar showed a vertical displacement of between $0.08 \mathrm{~m}$ and $0.10 \mathrm{~m}$. This would yield stiffness coefficients of between 22,000 N.m ${ }^{-1}$ and 27,500 N.m ${ }^{-1}$. The high bar used in the present study conforms with these results (Table 1).

Table 1. Results of the regressions performed on the displacements and loads from the static loading

\begin{tabular}{|c|c|c|c|c|}
\hline \multirow{2}{*}{$\begin{array}{c}\text { cable } \\
\text { tension } \\
(\mathrm{kN})\end{array}$} & \multicolumn{2}{|c|}{ vertical regression } & \multicolumn{2}{|c|}{ horizontal regression } \\
\hline & $\begin{array}{l}\text { coefficient } \\
(\mathrm{N} / \mathrm{m})\end{array}$ & $\begin{array}{c}\text { standard error } \\
(\mathrm{N})\end{array}$ & $\begin{array}{l}\text { coefficient } \\
(\mathrm{N} / \mathrm{m})\end{array}$ & $\begin{array}{c}\text { standard error } \\
\text { (N) }\end{array}$ \\
\hline 1.3 (slack) & -24757 & 60.4 & -20842 & 58.7 \\
\hline 1.5 (normal) & -25097 & 51.7 & -21837 & 58.6 \\
\hline 1.7 (tight) & -25170 & 61.8 & -21347 & 64.4 \\
\hline
\end{tabular}




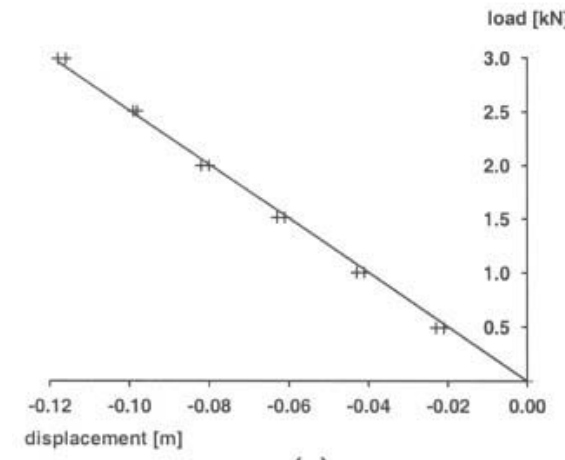

(a)

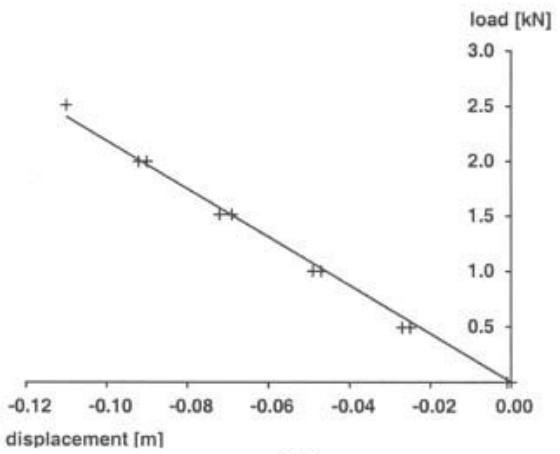

(b)

Figure 5 Typical plots and regression lines obtained from the static horizontal (a) and vertical (b) loading of the high bar.

Under the three loading conditions (cable tensions) there does not appear to be any significant difference in the stiffness of the high bar. Although there is a general trend for the stiffness of the bar to increase as the tension in the stabilising cables increases there is only a difference of $2 \%$ between the 'slack' and the 'tight' conditions. However, the bar does appear to be less stiff in the horizontal direction than in the vertical direction (Table 1). Over the three cable tensions used the bar was on average 15\% less stiff in the horizontal direction than in the vertical direction. This may be due to the design of the high bar. In the vertical direction the bar pivots about two pins which pass through the middle of the bar mountings. In the horizontal direction the mounting is designed so that it can twist about its vertical axis allowing the bar to be displaced more easily in the horizontal direction for a given load. In addition when the bar is loaded horizontally the tension in two of the stabilising cables is reduced whereas the tension in the remaining two cables increases. Compared with the vertical direction the movement of the bar is only partially constrained by the cables.

\section{Displacements of the bar}

The peak horizontal and vertical displacements of the bar during the three regular and three accelerated giant circles are given in Table 2. It can be seen that during the accelerated giant circles the peak displacements of the bar are larger than those obtained from the regular giant circles. Typical horizontal and vertical displacements of the bar are shown in Fig. 6a and $6 \mathrm{~b}$ for regular and accelerated giant circles, respectively.

Table 2. Peak horizontal and vertical displacements during the analysed regular and accelerated giant circles

\begin{tabular}{c|c|c} 
giant circle & $\begin{array}{c}\text { vertical displacement } \\
(\mathrm{m})\end{array}$ & $\begin{array}{c}\text { horizontal displacement } \\
(\mathrm{m})\end{array}$ \\
\hline regular & -0.093 & -0.077 \\
accelerated & -0.118 & -0.120
\end{tabular}




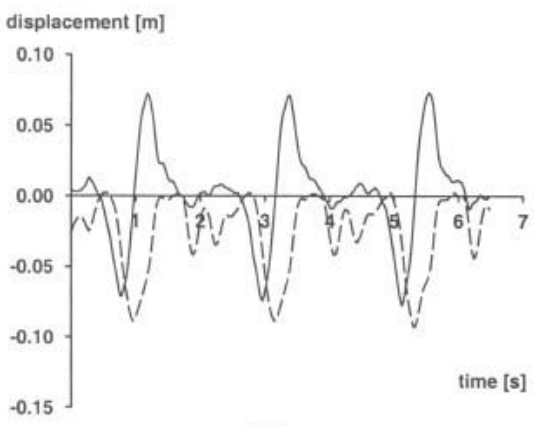

(a)

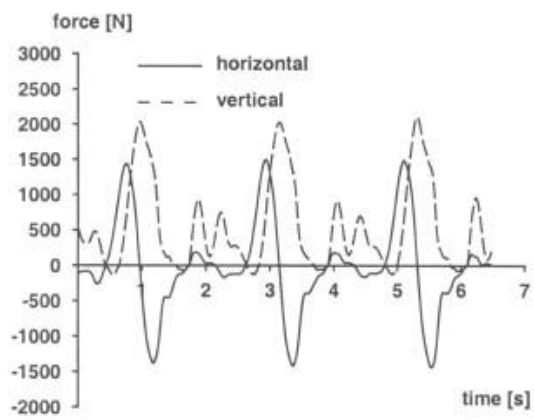

(c)

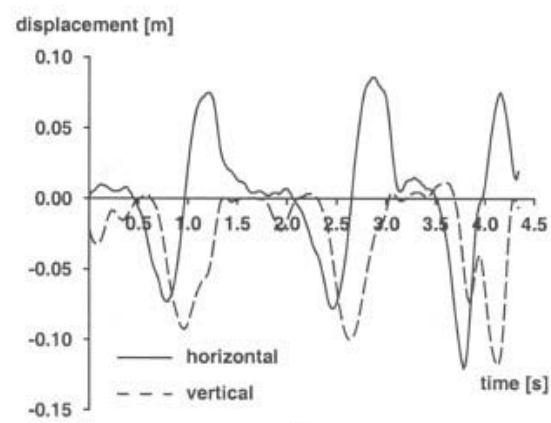

(b)

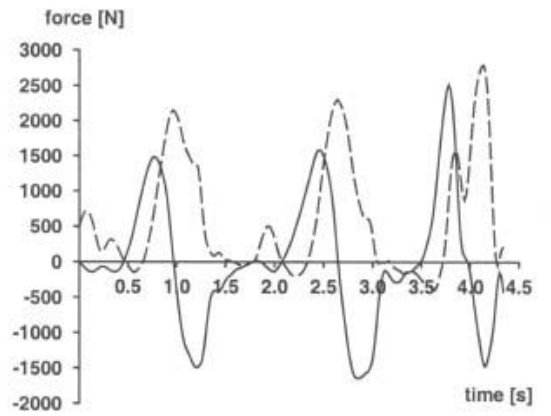

(d)

Figure 6 Horizontal and vertical bar displacements ( $a$ and $b$ ) and reaction forces recorded directly from the high bar (c and $d$ ) during three regular and three accelerated giant circles.

\section{Dynamic loading}

Observation of the strain data recorded during the calibration procedure revealed that there were horizontal and vertical offsets when zero load was applied to the bar. The channels on the strain gauge amplifier were 'zeroed' manually before the bar was loaded. However, when the strain was recorded with zero load applied to the bar a strain equivalent to $30 \mathrm{~N}$ was obtained in the horizontal direction and $3 \mathrm{~N}$ in the vertical direction. To correct for this error the appropriate amount of strain was subtracted from all data points and subsequently all strain recordings during the backward giant circle trials. Having corrected for the offsets the cross talk between the horizontal and vertical channels of strain data was found to be negligible (Hiley, 1998).

The peak horizontal and vertical reaction forces at the bar during the three regular and accelerated giant circles are given in Table 3. These forces are expressed in Newtons and bodyweights. To obtain the force in bodyweights the force in Newtons is divided by the subject's mass and the acceleration due to gravity. As for the displacements of the bar it can be seen that during the accelerated giant circles the reaction forces are larger than those obtained for the regular giant circles. Typical horizontal and vertical reaction forces of the bar are shown in Fig. 6c and 6d for regular and accelerated giant circles, respectively. The forces shown in Fig. 6c and 6d follow similar paths to those of the bar displacements shown in Fig. $6 \mathrm{a}$ and $6 \mathrm{~b}$ but reflected in the horizontal axis. The peak forces for the regular giant circles (Table 3) compare well with those obtained by Kopp and Reid (1980) who found the peak force in regular giant circles to be 3.57 bodyweights $(2208 \mathrm{~N})$. The peak forces during accelerated giant circles compare well with the peak forces of approximately $3100 \mathrm{~N}$ reported by Gervais (1993). 
Table 3. Peak horizontal and vertical reaction forces in Newtons and bodyweights recorded during the analysed regular and accelerated giant circles

\begin{tabular}{c|c|c} 
giant circle & $\begin{array}{c}\text { vertical force } \\
(\mathrm{N}, \mathrm{BW})\end{array}$ & $\begin{array}{c}\text { horizontal force } \\
(\mathrm{N}, \mathrm{BW})\end{array}$ \\
\hline regular & $2104,3.42$ & $1497,2.43$ \\
accelerated & $2789,4.53$ & $2513,4.08$
\end{tabular}

\section{Estimating reaction forces}

The rms differences between the reaction forces estimated using the stiffness coefficients from Table 1 and the recorded reaction forces are presented in Table 4. The rms differences in Table 4 have also been expressed as a percentage of the range of force. On average the rms values are less than $3.5 \%$ of the range of the recorded force. Fig. 7 shows the estimated horizontal and vertical reaction forces for the three regular (Fig. 7a and 7b) and three accelerated giant circles (Fig. 7c and 7d) using the regression coefficients obtained with the normal cable tension.

Table 4. Rms and percentage difference between estimated and recorded reaction forces during regular and accelerated giant circles under three cable tensions

\begin{tabular}{c|c|c|c|c}
$\begin{array}{c}\text { cable } \\
\text { tension } \\
(\mathrm{kN})\end{array}$ & $\begin{array}{c}|c| \\
\text { regular } \\
(\mathrm{N}, \%)\end{array}$ & $\begin{array}{c}\text { horizontal rms } \\
(\mathrm{N}, \%)\end{array}$ & $\begin{array}{c}\text { acrtical rms } \\
(\mathrm{N}, \%)\end{array}$ & $\begin{array}{c}\text { horizontal rms } \\
(\mathrm{N}, \%)\end{array}$ \\
\hline 1.3 (slack) & $97.5,4.3 \%$ & $73.7,2.5 \%$ & $112.2,3.5 \%$ & $66.4,1.6 \%$ \\
1.5 (normal) & $107.5,4.8 \%$ & $88.5,3.0 \%$ & $122.2,3.8 \%$ & $96.9,2.3 \%$ \\
1.7 (tight) & $109.7,4.9 \%$ & $79.9,2.7 \%$ & $124.4,3.9 \%$ & $80.2,1.9 \%$
\end{tabular}




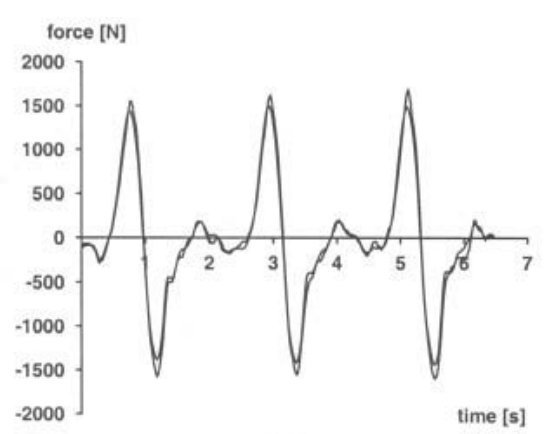

(a)

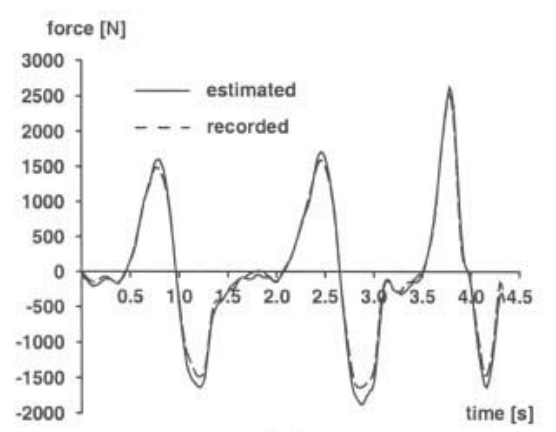

(c)

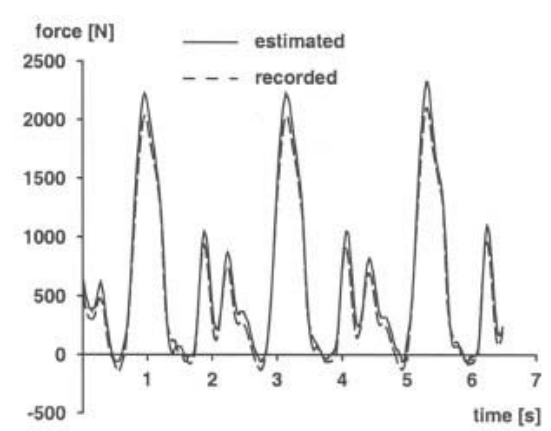

(b)

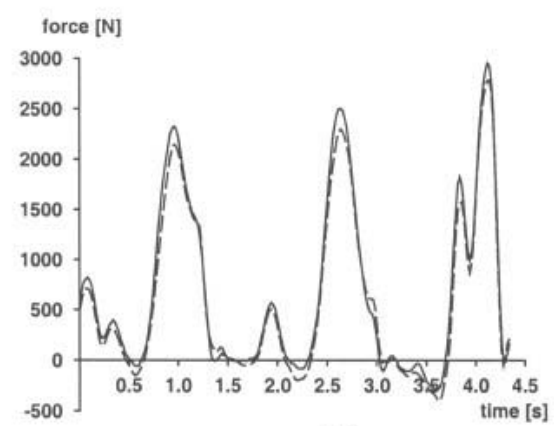

(d)

Figure 7 Comparison between estimated and recorded forces in the horizontal and vertical directions for three regular ( $a$ and $b$ ) and three accelerated ( $c$ and d) giant circles.

It has been noted that the high bar was less stiff in the horizontal direction (Table 1). To determine the effect of assuming the bar to be equally stiff in the horizontal and vertical directions the vertical stiffness values were used to estimate the reaction forces in the horizontal direction. The results revealed that using the vertical stiffness of the bar to estimate the horizontal reaction forces leads to an increase in the rms differences. However, for the given cable tensions the rms differences are on average $202 \mathrm{~N}$ or within $6 \%$ of the range of force. Using the current apparatus it is recommended that if it is not possible to load the high bar in the horizontal direction an appropriate adjustment should be made for the horizontal stiffness coefficient. In the present study the bar was found to be $15 \%$ less stiff in the horizontal direction and this could be used as a basis for the adjustment.

During the three regular and three accelerated giant circles there were a total of 18 peaks in the horizontal and vertical force traces. The estimated peak forces tended to overestimate the measured values which can be seen in Fig. 7. However, on average the present method was able to estimate the peak forces to within $7 \%$ of the recorded value. This value compares favourably with the $24 \%$ obtained by Gervais (1993) using the inverse dynamic method and forces recorded using strain gauges.

\section{Field based calibration}

For each of the three cable tensions used in the static loading a simplified vertical loading was performed. This field based static loading procedure was designed so that it could be carried out in the gymnasium or competition arena and would require no sophisticated equipment or floor/wall mountings. The loading could be performed before or after a competition at the same time as the calibration of the movement space for the threedimensional video analysis. The bar was loaded using varying numbers of people seated on a static swing suspended at the bar centre. The maximum load applied was four people, the 
equivalent of $2.53 \mathrm{kN}$. The results of the regressions performed on the vertical bar displacements and the load applied to the bar using the field based method are presented in Table 5. The stiffness coefficients (regression coefficients) presented in Table 5 are on average 3.8\% larger than the equivalent values presented in Table 1. Using the new stiffness coefficients to estimate the vertical reaction forces results in an average rms difference of 143.4 N (5.4\%). Fig. 8 shows the estimated vertical force using the stiffness coefficient from the field based static loading overlaid with the force recorded directly from the high bar. The agreement between the estimated and measured forces was good, although there was again a tendency to overestimate the peak reaction forces.

Table 5. Results of the regressions performed on the displacements and loads from the field based static loading

\begin{tabular}{c|c|c}
$\begin{array}{c}\text { cable } \\
\text { tension } \\
(\mathrm{kN})\end{array}$ & $\begin{array}{c}\mid c \\
\text { vertical regression } \\
(\mathrm{N} / \mathrm{m})\end{array}$ & $\begin{array}{c}\text { standard error } \\
(\mathrm{N})\end{array}$ \\
\hline 1.3 (slack) & -25607 & 14.1 \\
1.5 (normal) & -25989 & 21.3 \\
1.7 (tight) & -26289 & 20.9
\end{tabular}

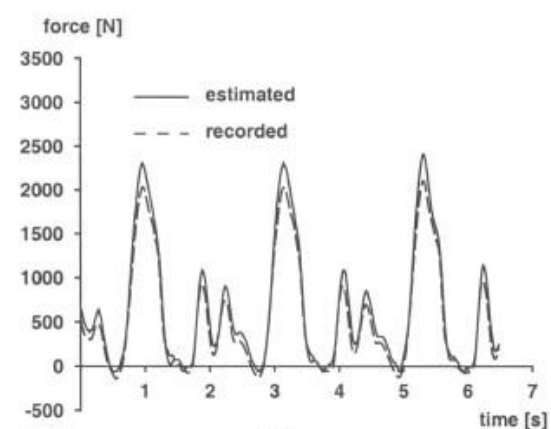

(a)

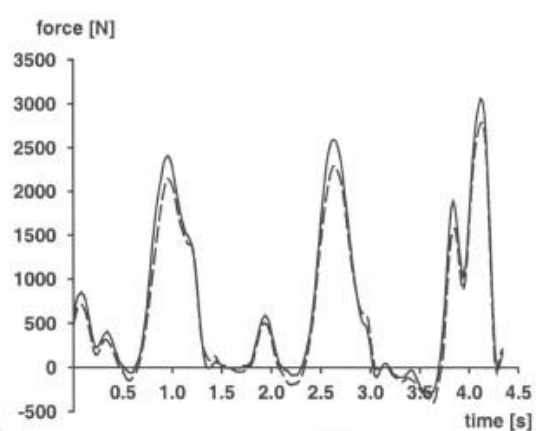

(b)

Figure 8 Estimated vertical reaction forces using the stiffness coefficient obtained from the field based loading for three regular (a) and three accelerated (b) backward giant circles.

\section{Conclusions}

Using a static calibration and displacements of the bar determined from video analysis the reaction forces experienced by a gymnast circling the high bar can be accurately estimated. Although there was a tendency with the present method to over-estimate the peak forces, superior results to those obtained using an inverse dynamics analysis (Gervais, 1993) were achieved. It is important to note that the bar used in the present study was less stiff in the horizontal direction. This is likely to be the case for all competition high bars due to the arrangement of the stabilising cables and mountings to the uprights. If only a vertical calibration is possible in the competition arena (or gymnasium) an appropriate adjustment to the horizontal stiffness of the bar should be made. It was also interesting to note the small 
changes in bar stiffness coefficients with increasing tension in the stabilising cables. It would therefore be possible to calibrate the bar before and/or after a competition. Even if a gymnast or coach altered the tension in the stabilising cables it is unlikely to greatly effect the forces determined using the present method.

Since the proposed method relies on stiffness coefficients and bar displacements to estimate the reaction forces it is speculated that accuracy could be increased with improved video based bar displacement data. In the present study the width of the field of view from which the dynamic bar displacements were obtained was around $6 \mathrm{~m}$. This would allow a kinetic and kinematic analysis of the swinging to be performed. Having a third video camera with a small field of view zoomed in on the centre of the bar is expected to improve the accuracy of the proposed method. The present method also used a high bar that was marked at its centre. If it is not possible to mark the bar, an estimation of the location of the bar centre may be made from averaging reconstructed locations of the centre of the hands. An rms difference between the average location of the hands and the centre of the bar of $0.005 \mathrm{~m}$ was obtained for one of the accelerated giant circles used in the present study. Again it is anticipated that the accuracy would improve given a smaller field of view.

\section{Acknowledgments}

The authors wish to acknowledge the support of British Gymnastics and Continental Sports Ltd, UK.

\section{References}

Abdel-Aziz, Y.I. and Karara, H.M. (1971). Direct linear transformation from comparator coordinates into object space coordinates in close-range photogrammetrey (ASP Symposium on Close-Range Photogrammetrey). Falls Church, VA: American Society of Photogrammetrey. pp. 1-18.

Arampatzis, A. and Brüggemann, G-P. (1999). Mechanical energetic processes during the giant swing exercise before dismounts and flight elements on the high bar and uneven parallel bars. Journal of Biomechanics, 32, 811-820.

Brüggemann, G-P., Cheetham, P.J., Alp, Y. and Arampatzis, D. (1994). Approach to a biomechanical profile of dismounts and release-regrasp skills of the high bar. Journal of Applied Biomechanics, 10, 291-312.

Continental Sports Ltd, UK. (1994). Norm-testing of functional properties of FIG equipment and FIG mats. Continental Sports Ltd. Huddersfield.

Enchun, L. (1989). A study of the technique principals and characteristics of the one arm giant swing backward. GRASP, 7, 94-96.

Gervais, P. (1993). Calculation of reaction forces at the hands on the horizontal bar from positional data. In: Proceedings of the XIV th Congress of the International Society of Biomechanics (pp. 468-469). University of South Paris. Paris.

Hiley, M.J. (1998). Mechanics of the giant circle on high bar. PhD thesis, Loughborough University.

Fédération Internationale de Gymnastique. (1993). Measurements, dimensions and forms. FIG. Switzerland.

Ishii, K. and Komatsu, T. (1987). Changes of kinetic parameters and forces on the horizontal bar backward giant swing. In: Diagnostics, Treatment and Analysis of Gymnastic Talent (eds T.B. Hoshizaki, J.H. Salmela and B. Petiot), pp. 107-117. Sports Psyche Editions. Montreal.

Kerwin, D.G. (1995). Apex/Target high resolution video digitising system. In: Procedings of the Biomechanics Section of the British Association of Sports and Exercise Science (ed 
J. Watkins), pp. 1-4. Glasgow: BASES.

Kopp, P.M. and Reid, J.G. (1980). A force torque analysis of giant swings on the horizontal bar. Canadian Journal of Applied Sports Science, 5, 98-102.

Neal, R.J., Kippers, V., Plooy, D. and Forwood, M.R. (1995). The influence of hand guards on forces and muscle activity during giant swings on the high bar. Medicine and Science in Sports and Exercise, 27, 1550-1556.

Wood, G.A. and Jennings, L.S. (1979). On the use of spline functions for data smoothing. Journal of Biomechanics, 12, 477-479. 